\title{
Using The Jeopardy Game To Enhance Student Understanding Of Accounting Information Systems (AIS) Exam Material
}

Sarah Bee, (E-mail: bees@seattleu.edu), Seattle University

David C. Hayes, (E-mail: dhayes1@1su.edu), Louisiana State University

\begin{abstract}
Accounting research has included many suggestions for increasing active learning in the classroom. These include journal writing, role-playing and playing games (Haywood, McMullen, and Wygal 2004). The use of games in class is an effective tool to stimulate interest, reduce boredom, and enhance learning among the students. The popular TV game show "Jeopardy!' was employed to review students for an undergraduate accounting information systems (AIS) exam. Pre/post test results reflect a significant increase in the students' understanding of AIS exam material that was covered. Overall the students agreed that the game was enjoyable and requested that they be able to review for other exams in a similar manner.
\end{abstract}

\section{Introduction}

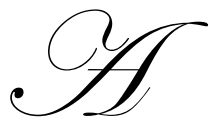

ccounting information systems (AIS) courses cover a number of diverse topics. The breadth of subject matter creates a challenge for students as they try to assimilate the topics in preparation for exams. A typical exam for an AIS course may encompass topics ranging from computer controls to documents used in the revenue cycle. For example, an exam covering chapters eight through eleven in Romney and Steinbart's Accounting Information Systems, ${ }^{\text {th }}$ edition would cover: A) Computer Based Information Systems Control, B) Computer Fraud and Security, C) Computer Audit, and D) the Revenue and Expenditure Cycles. The lack of a common theme among these topics adds a level of difficulty to exam review and preparation over accounting courses that have a more contiguous subject matter.

An exam review helps students recognize the important points of the course material and guides their study efforts / learning. There are different avenues for students to use in the review process. The publishers of textbooks often provide supplementary materials that include both test questions and a test review. An enhancement to publisher provided test review materials is an in-class review of concepts. This can take the form of the professor going over important concepts or even asking questions and soliciting answers from the students. A more engaging way of presenting a test review is to create a game with the questions and answers.

The National Institute of Education identified active learning as the number one priority in American higher education in a 1984 report (Fox-Cardamone and Rue 2003). Research in educational reform suggests that active learning enhances student understanding and retention. Accounting research has included many suggestions for increasing active learning in the classroom. These include journal writing, role-playing and playing games (Haywood, McMullen, and Wygal 2004). The use of games as a learning aid is becoming wide spread as evidenced by the inclusion in educational journals of games (Keck 2000). Game play reinforces the concepts taught in class and is an effective tool to stimulate interest and reduce boredom among the students.

An example of active learning is to use a game show format to review material. Jeopardy is used in an undergraduate AIS class to review exam material. While prior studies (Burns and Benoit 2002) have used paper and pencil or (Richard Sleight, PhD., Seattle Pacific University) to present the game, this study developed the game using Microsoft's Excel. Excel offers the natural advantage of being able to calculate items such as group's scores 
or points remaining on the game board. In addition, hyperlinks and macros are employed to allow the game to be played with seamless transition between worksheets. The worksheets are designed to allow instructors to easily switch between topics/questions or to insert their own topics/questions. Additionally, the Jeopardy game has the advantage of containing a pre-set number of questions with varying scores for different levels of difficulty. The game is also widely recognized by students, so there is little or no learning curve involved in implementing the game.

\section{IMPLEMENTING THE JEOPARDY GAME}

\section{A. Preparation Prior To Class Time}

The first thing the instructor will want to do is set up the Jeopardy game. To open the file, the instructor's macro security level must be on "medium." To switch the macro security level, click on "Tools", "Macro" and "Security" and choose "Medium" as the security level. When subsequently opening the file and at the security warning, click on "Enable Macros" and this will allow the program to run and will bring the instructor to the Jeopardy main menu (see Exhibit 1).

Exhibit 1

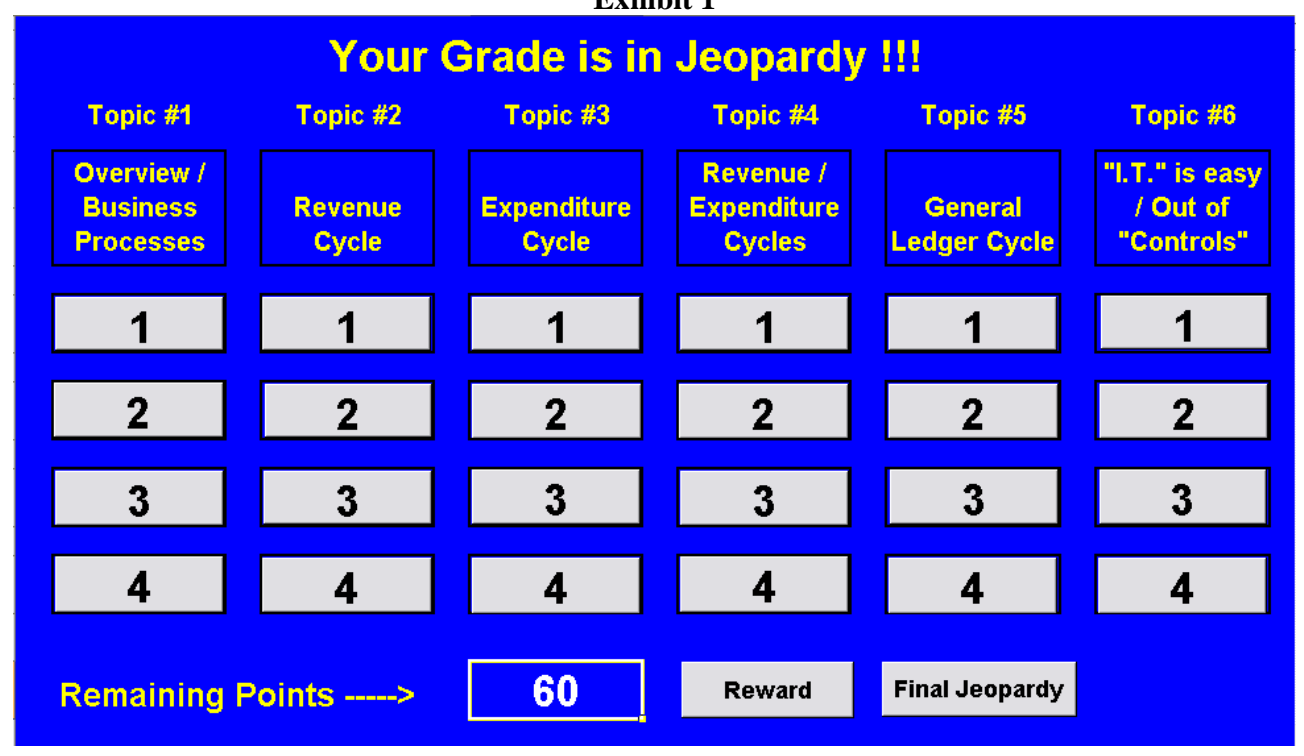

There are two modifications that the instructor may want to make at this point, if the entire main menu is not visible. First, the instructor should close some of the toolbars to increase the viewable menu. This can be done by clicking on "View", "Toolbars" and de-selecting those options not needed. We generally leave two toolbars available (Standard and Formatting) and de-select the rest. Additionally, the instructor may need to adjust the screen formatting. This can be done by changing the viewable percentage on the Standard Toolbar.

Once the main menu is visible, the instructor will now need to determine what reward the students are playing for. Click on the "Reward" tab at the bottom of the worksheet. In the reward sheet the instructor can change the game to regular points by highlighting cell "D7" and deleting the word "bonus". To change the value of the (bonus) points, click on the "Questions" tab at the bottom of the screen. This sheet allows the instructor to set the maximum points earned. Change the amount the point values decrease by here. Entering the value " 2 " here would change the rewards to " 5 ", " 3 ", " 1 " and " 0 " for the rest of the groups. The spreadsheet is designed to be userfriendly in that most of the items the instructor is allowed to change are designated with blue highlighting. Note that the minimum a team can receive is zero points - if desired, altering the formulas in column "C" in the "Reward" 
sheet can change this.

Next, the topics and questions need to be selected. To change the topics, click on the "Quest_2" tab (NOT the "questions" tab) and type in your desired topics in the blue highlighted area (see Exhibit 2).

Exhibit 2

\begin{tabular}{|c|c|c|}
\hline ppic \# & Top & \\
\hline 10 & Overview/ Business Processes & $<---$ You can change these, but need to change the questions below to match the topic \& point value. \\
\hline 20 & Revenue Cycle & $<---$ You can change these, but need to change the questions below to match the topic \& point value. \\
\hline 30 & Expenditure Cycle & $<---$ You can change these, but need to change the questions below to match the topic \& point value. \\
\hline 40 & Revenue / Expenditure Cycles & \&--- You can change these, but need to change the questions below to match the topic \& point value. \\
\hline 50 & General Ledger Cycle & <--- You can change these, but need to change the questions below to match the topic \& point value. \\
\hline 60 & "I.T." is easy/Out of "Controls" & $<---$ You can change these, but need to change the questions below to match the topic \& point value. \\
\hline 70 & Databases (not ready) & $<---$ You can change these, but need to change the questions below to match the topic \& point value. \\
\hline 80 & Flowcharting (not ready) & \&--- You can change these, but need to change the questions below to match the topic \& point value. \\
\hline 90 & Excel (Not ready) & \&--- You can change these, but need to change the questions below to match the topic \& point value. \\
\hline 100 & Systems Development Life Cy & $<--$ You can change these, but need to change the questions below to match the topic \& point value. \\
\hline
\end{tabular}

The spreadsheet allows the instructor to build a bank of questions for up to 10 topics so a new game of different topics can be easily selected. Note that if the instructor changes the topics, they will also need to change the questions and answers to match the new topic.

Next the instructor can scan through the question bank (see Exhibit 3) and change the questions to match the topics as desired by typing in new questions and answers in the blue highlighted areas. The "Pt Value" is the point assigned to each question. The Game \# indicates four different games that can be selected (game 1, 2, 3, or 4).

Exhibit 3

\begin{tabular}{|c|c|c|c|c|c|}
\hline & & & $\mathrm{Pt}$ & & \\
\hline Game \# & Topic \# & Topic & Value & Select / Change Questions Below & Answer \\
\hline 1 & 10 & Overview / Business Processes & & $\begin{array}{l}\text { This special journal is used to make the recording of our credit sales more } \\
\text { efficient. }\end{array}$ & What is the sales journal. \\
\hline 2 & 10 & Overview / Business Processes & & $\begin{array}{l}\text { This special journal is used to make the recording of our cash sales more } \\
\text { efficient. }\end{array}$ & What is the cash receipts journal. \\
\hline 3 & 10 & Overview / Business Processes & & $\begin{array}{l}\text { This special journal is used to make the recording of our purchases on account } \\
\text { more efficient. }\end{array}$ & What is the purchases journal. \\
\hline 4 & 10 & Overview / Business Processes & & $\begin{array}{l}\text { This special journal is used to make the recording of our cash payments more } \\
\text { efficient. }\end{array}$ & What is the cash disbursements journal. \\
\hline 1 & 10 & Overview / Business Processes & & $\begin{array}{l}\text { Information that reduces uncertainty, improves decision makers' ability to make } \\
\text { predictions, or confirms or corrects their prior expectations. }\end{array}$ & What is Relevant information. \\
\hline 2 & 10 & Overview / Business Processes & & $\begin{array}{l}\text { When two knowledgeable people acting independently each produce the same } \\
\text { information. This information is }\end{array}$ & What is Verifiable. \\
\hline 3 & 10 & Overview / Business Processes & & $\begin{array}{l}\text { Information that is free from error or bias and accurately represents the events } \\
\text { or activities of the organization. }\end{array}$ & What is reliable information. \\
\hline 4 & 10 & Overview / Business Processes & & $\begin{array}{l}\text { When two knowledgeable people acting independently each produce the same } \\
\text { information. This information is }\end{array}$ & What is Verifiable. \\
\hline 1 & 10 & Overview / Business Processes & & $\begin{array}{l}\text { In transaction processing, posting to "T" accounts is generally the _ } 1 \text { st / } 2 \text { nd / } \\
3 \mathrm{rd} / 4 \text { th / } 5 \text { th / } 6 \text { th__ activity. }\end{array}$ & What is third. \\
\hline 2 & 10 & Overview / Business Processes & 3 & $\begin{array}{l}\text { In transaction processing, capturing data on source documents is generally the } \\
\text { 1st } / 2 \text { nd } / 3 \mathrm{rd} / 4 \text { th } / 5 \text { th } / 6 \text { th _ activity. }\end{array}$ & What is first. \\
\hline
\end{tabular}

Once the topics and corresponding questions/answers are entered, the instructor needs to choose the topics (see Exhibit 4) and the game. Click on the "questions" tab and selecting the desired topics and game by changing the blue highlighted values. 
Exhibit 4

\begin{tabular}{|l|l|}
\hline & Topics Selected \\
\hline Select Topic \#1 by choosing a number --> & $\mathbf{1 0}$ Overview/ Business Processes \\
\hline Select Topic \#2 by choosing a number --> & 20 Revenue Cycle \\
\hline Select Topic \#3 by choosing a number --> & 30 Expenditure Cycle \\
\hline Select Topic \#4 by choosing a number --> & $\mathbf{4 0}$ Revenue / Expenditure Cycles \\
\hline Select Topic \#5 by choosing a number ---> & $\mathbf{5 0}$ General Ledger Cycle \\
\hline Select Topic \#6 by choosing a number ---> & $\mathbf{6 0}$ "I.T." is easy / Out of "Controls" \\
\hline
\end{tabular}

The instructor can change the blue highlighted number, to change to a new game $(1,2,3$ or 4$)$ with the same topics, but different questions. Try changing the " 1 " to a "2" and notice how the questions change in the Question and Answer columns.

Next, the instructor will need to click on the "Key" tab and decide on a Final Jeopardy question and answer. If the instructor does not like the pre-filled question, then they should type in their new question and answer in the blue highlighted cells "F32" and "H32" respectfully.

Now that the question and answer board is ready to play, it is recommended that the instructor print out a copy of the answer key. When playing the game, the instructor can look at the answer to the question before showing the students the question.

Next the instructor should print out the optional table tents (see Exhibit 5). Each team will be given a table tent that includes a place for group members' names and the Final Jeopardy answer. The table tent also identifies the teams to the instructor during the game for scoring purposes. It is suggested that the instructor bring eight pens to class for the groups to use to deter cheating.

Exhibit 5

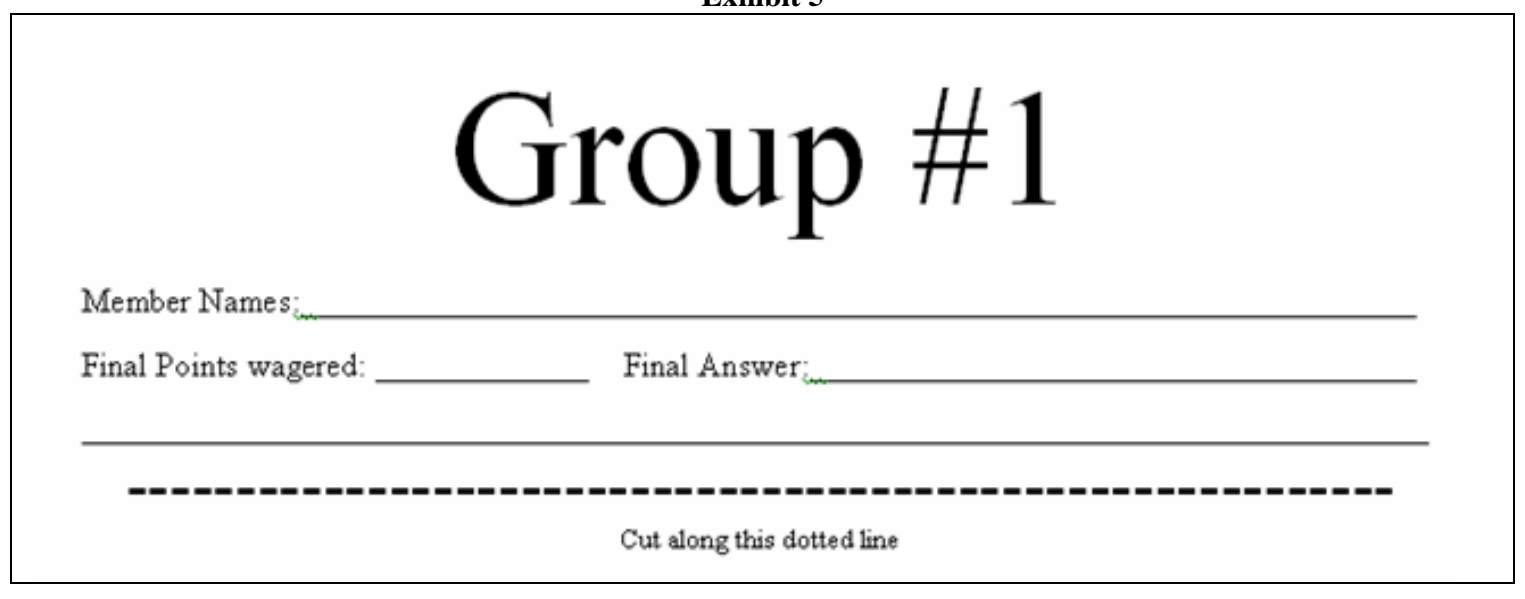

Lastly the instructor should practice loading the file on the computer where the game will be played to ensure that the macro security level is set to medium and that the game board is viewable by all students. 
Additionally, the instructor should perform a "save as" and rename the file so that they will always have a blank spreadsheet and will not have to reset the points on the main menu. If the instructor teaches several sections, then they might want to create a spreadsheet for each section so it is easy to start the game for each section by simply opening the file for that section.

\section{B. Preparation During Class Time And Prior To Playing The Game}

First the instructor should load the game on the classroom computer. The students are then informed that their grades are about to be put in Jeopardy - the fun way. The students are informed of what they are playing for by clicking on the "Reward" button on the "Topics" menu and displaying the available points. It is suggested that the instructor solicit a volunteer(s) to help determine the "buzz in" order and to help track which groups got the right / wrong answers during the questions. A suggestion is to offer the assistant $1 / 2$ of the possible bonus points available. Alternatively for larger classes (greater than 32 students), if the game is played more than one time, the instructor can get non-participants to assist them.

For those students participating in the game, tell them to form up to eight groups (depending on class size). Exceeding eight groups is problematic for the instructor as it is difficult to detect which team raised their hand first and the scoreboard is only designed to accommodate eight groups. It is recommended not to have groups larger than three or four members and to let them form the groups on their own.

Once the groups are formed, the instructor hands out the table tents and pens and instructs the group members to write their names on the tent so that the instructor can later identify who gets the bonus points when the table tents are picked up.

\section{Playing The Game}

Once the game is set and the groups formed, the instructor informs the groups of the following rules:

- Groups can ask any topic or point value in their preferred order. The group with the first correct answer decides which question will be asked next.

- $\quad$ The questions are displayed for the students to read and discuss among their groups, the first group to raise their hand gets to attempt the questions first. If the first group misses the questions, then the next hand that was raised goes second and so on.

- $\quad$ One person from each team is designated as the "hand raiser / buzzer" and "question answerer." This helps to reduce the number of hands the instructor / volunteer have to determine were raised first, second, etc.

- $\quad$ All answers must be in the form of a question.

- $\quad$ Once your group is called upon to answer a question, your group has five seconds to respond.

- $\quad$ Books may/may not be used in the game (instructor's choice).

- $\quad$ Points will be deducted for wrong answers.

- The only groups eligible to play in "Final Jeopardy" for bonus points are those groups with a cumulative positive score.

- $\quad$ Groups can wager up to the total cumulative points earned during regular Jeopardy for the Final Jeopardy question.

- $\quad$ Winners will be determined after adding or subtracting the Final Jeopardy points.

The instructor randomly selects a group to have initial control of the topic selection and point value. The group will select a topic and point value, the instructor must be very careful to click on the correct item because once they are selected, the values are reduced to zero and can not be reset unless you restart the game. It is suggested that after the group calls out the topic and point value that the instructor look up the correct answer on the printed out key, then click on the point value selected under the desired topic. Once the instructor clicks on the item selected, a macro reduces that option to zero and takes the students to the corresponding question. For example, if the first question asked is the 3 point option under the revenue cycle (topic \#2), the following question will be displayed: 
Exhibit 6

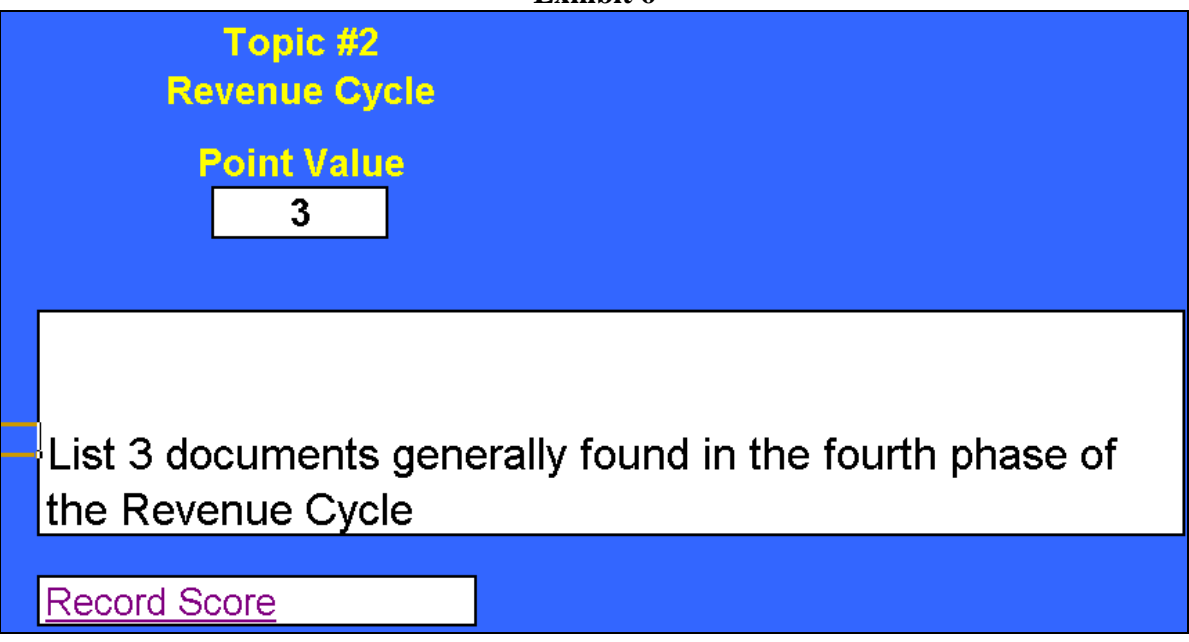

After the question is answered correctly, the instructor clicks on the "Record Score" box and is hyperlinked to the scoreboard (see Exhibit 7) to the proper row (but not necessarily the proper group) to record the scores.

Exhibit 7

\begin{tabular}{|c|c|c|c|c|c|c|c|c|c|}
\hline Topic \# & pts & $\begin{array}{l}\text { Group \#1 } \\
\text { Right Wrong }\end{array}$ & $\begin{array}{l}\text { Group \#2 } \\
\text { Right Wrong }\end{array}$ & $\begin{array}{l}\text { Group \#3 } \\
\text { Right Wrong }\end{array}$ & $\begin{array}{l}\text { Group \#4 } \\
\text { Right Wrong }\end{array}$ & $\begin{array}{l}\text { Group \#5 } \\
\text { Right Wrong }\end{array}$ & $\begin{array}{l}\text { Group \#6 } \\
\text { Right Wrong }\end{array}$ & $\begin{array}{l}\text { Group \#7 } \\
\text { Right Wrong }\end{array}$ & $\begin{array}{l}\text { Group \#8 } \\
\text { Right Wrong }\end{array}$ \\
\hline Overview / Business Proces & 1 & 0 & $\mathbf{0}$ & 0 & 0 & 0 & $\mathbf{0}$ & $\mathbf{0}$ & $\mathbf{0}$ \\
\hline Overview / Business Proces & 2 & 0 & $\mathbf{0}$ & 0 & 0 & 0 & $\mathbf{0}$ & $\mathbf{0}$ & $\mathbf{0}$ \\
\hline Overview / Business Proces & 3 & 0 & $\mathbf{0}$ & 0 & 0 & 0 & $\mathbf{0}$ & $\mathbf{0}$ & $\mathbf{0}$ \\
\hline Overview / Business Proces & 4 & 0 & $\mathbf{0}$ & 0 & 0 & 0 & 0 & 0 & $\mathbf{0}$ \\
\hline Revenue Cycle & 1 & 0 & $\mathbf{0}$ & 0 & 0 & 0 & $\mathbf{0}$ & $\mathbf{0}$ & $\mathbf{0}$ \\
\hline Revenue Cycle & 2 & 0 & $\mathbf{0}$ & 0 & 0 & 0 & $\mathbf{0}$ & $\mathbf{0}$ & $\mathbf{0}$ \\
\hline Revenue Cycle & 3 & 3 & $\mathbf{0}$ & 0 & 0 & 0 & $\mathbf{0}$ & $\mathbf{0}$ & $\mathbf{0}$ \\
\hline Revenue Cycle & $\overline{4}$ & 0 & 0 & 0 & 0 & 0 & 0 & 0 & 0 \\
\hline Expenditure Cycle & 1 & 0 & $\mathbf{0}$ & 0 & 0 & 0 & $\mathbf{0}$ & 0 & $\mathbf{0}$ \\
\hline Expenditure Cycle & 2 & 0 & $\mathbf{0}$ & 0 & 0 & 0 & $\mathbf{0}$ & $\mathbf{0}$ & $\mathbf{0}$ \\
\hline Expenditure Cycle & 3 & 0 & $\mathbf{0}$ & 0 & 0 & 0 & $\mathbf{0}$ & $\mathbf{0}$ & $\mathbf{0}$ \\
\hline Expenditure Cycle & 4 & 0 & 0 & 0 & 0 & 0 & 0 & 0 & 0 \\
\hline Revenue / Expenditure Cycli & 1 & 0 & $\mathbf{0}$ & 0 & 0 & 0 & $\mathbf{0}$ & 0 & $\mathbf{0}$ \\
\hline Revenue / Expenditure Cycli & 2 & 0 & $\mathbf{0}$ & 0 & 0 & 0 & $\mathbf{0}$ & $\mathbf{0}$ & $\mathbf{0}$ \\
\hline Revenue / Expenditure Cycli & 3 & 0 & $\mathbf{0}$ & 0 & 0 & 0 & $\mathbf{0}$ & $\mathbf{0}$ & $\mathbf{0}$ \\
\hline Revenue / Expenditure Cycli & 4 & 0 & 0 & 0 & 0 & 0 & 0 & 0 & 0 \\
\hline General Ledger Cycle & 1 & 0 & $\mathbf{0}$ & 0 & 0 & 0 & $\mathbf{0}$ & 0 & $\mathbf{0}$ \\
\hline General Ledger Cycle & 2 & 0 & $\mathbf{0}$ & 0 & 0 & 0 & $\mathbf{0}$ & 0 & $\mathbf{0}$ \\
\hline General Ledger Cycle & 3 & 0 & $\mathbf{0}$ & 0 & 0 & 0 & $\mathbf{0}$ & 0 & $\mathbf{0}$ \\
\hline General Ledger Cycle & 4 & 0 & 0 & 0 & 0 & 0 & 0 & 0 & 0 \\
\hline "१.T." is easy / Out of "Contr! & 1 & 0 & $\mathbf{0}$ & 0 & 0 & 0 & $\mathbf{0}$ & $\mathbf{0}$ & $\mathbf{0}$ \\
\hline "१.T." is easy / Out of "Contri & 2 & 0 & $\mathbf{0}$ & 0 & 0 & 0 & $\mathbf{0}$ & $\mathbf{0}$ & $\mathbf{0}$ \\
\hline "१.T." is easy / Out of "Contr! & 3 & 0 & $\mathbf{0}$ & 0 & 0 & 0 & $\mathbf{0}$ & 0 & $\mathbf{0}$ \\
\hline "१.T." is easy / Out of "Contrı & 4 & 0 & 0 & 0 & 0 & 0 & 0 & 0 & 0 \\
\hline Regular Jeopardy & & 3 & $\mathbf{0}$ & 0 & 0 & 0 & $\mathbf{0}$ & $\mathbf{0}$ & $\mathbf{0}$ \\
\hline Final Jeopardy & & 0 & 0 & 0 & 0 & 0 & $\mathbf{0}$ & $\mathbf{0}$ & $\mathbf{0}$ \\
\hline I & & $\mathbf{u}$ & $\mathbf{U}$ & 3 & U & 0 & 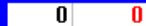 & $\mathbf{U}$ & 0 \\
\hline
\end{tabular}

The instructor has to record the point value for that question for each of the groups that guessed in the proper columns. The instructor records a corresponding score in the "right" column for the group with the correct answer and corresponding scores in the "wrong" columns for the group(s) who guessed incorrectly. For example, if you just finished a question on Topic 2 (Revenue Cycle) worth 3 points, then you would be at the cell in Exhibit 11 above. If group \#1 and group \#2 attempted an answer and missed it and group \#3 gave the correct answer, then the 
scores would be recorded as shown above in Exhibit 11. If the instructor accidentally records the wrong point value in a row, then a pink " $X$ " will indicate an error. Once the error is corrected, the " $X$ " will disappear.

After recording the scores, the instructor clicks on the "Return to topics" hyperlink that takes the players back to the main Jeopardy menu. Now the board should only show 57 points remaining since the 3 point question was answered. The group with the correct answer selects the next topic and point value. This process is continued until all the questions have been asked or until the time is finished (if a time constraint is enforced). The scoreboard keeps a cumulative total for each of the groups during the regular Jeopardy game. Any group that has more cumulative regular Jeopardy total points that are in the "wrong" column will be in the "red," will have negative total points, and not be allowed to participate in "final jeopardy". Any group that has more cumulative regular Jeopardy total points in the "right" column will be in the "black," will have positive total points, and will be allowed to participate in "Final Jeopardy".

At the end of the regular game, "Final Jeopardy" is played. The instructor selects "Final Jeopardy" from the "Topics" menu and the following scoring recap appears.

Exhibit 8

\section{Welcome to Final Jeopardy!!! Here are your Standings}

\section{Points}

Return to Regular Jeopardy

\section{Continue with Final} Jeopardy

Group \#1 -3 Sorry but your group doesn't have any points to play final jeopardy.

Group \#2 -3 Sorry but your group doesn't have any points to play final jeopardy.

Group \#3 3 Write your final points wagered on your table tent. Good Luck

Group \#4 2 Write your final points wagered on your table tent. Good Luck

Group \#5 0 Sorry but your group doesn't have any points to play final jeopardy.

Group \#6 0 Sorry but your group doesn't have any points to play final jeopardy.

Group \#7 0 Sorry but your group doesn't have any points to play final jeopardy.

Group \#8 0 Sorry but your group doesn't have any points to play final jeopardy.

Write the number of points you want to wager on your group label.

Groups with negative points cannot participate in Final Jeopardy. So in the above illustration, only group \#3 and group \#4 would be allowed to participate. The participating groups are informed to analyze the scores strategically and to use the pens provided to write on their table tents the desired points to wager. Participating groups are then informed they will have 30 seconds to answer the "Final Jeopardy" question. Once all participating groups have indicated they are ready, the instructor clicks on the "Continue with Final Jeopardy" button to reveal the Final Jeopardy question.

After the Final Jeopardy answers are revealed, the instructor clicks on the hyperlink "Record Scores" and posts the final jeopardy results on the scoreboard. It is suggested that the instructor collect the table tents as a record of who gets the pre-determined bonus points. Additionally, the instructor should save the file to latter print out the scoreboard. Hopefully your students are better prepared for the upcoming exam and had fun in the process! 


\section{PRE/POST TEST RESULTS OF LEARNING BY EMPLOYING THE JEOPARDY GAME}

A test was given to students to assess the effectiveness of the Jeopardy game and its ability to promote learning. Forty-three undergraduate AIS students at a large university were informed prior to class that they would be given a comprehensive quiz the next class period and that the quiz would count as a regular quiz grade. They were informed that this quiz would be part of their exam review in that there would be representative exam questions on the quiz. The students were not made aware that there would be a follow-up (post-test) quiz. A comprehensive pre/post quiz was developed to test learning effects from the Jeopardy game. The questions on the quizzes were developed around broad concepts in which the students would not necessarily see the same question twice during the pre and post-test. For example, during the pre-test, students may have answered questions relating to the second phase of the revenue cycle, during the Jeopardy game, they may have answered questions relating to the third phase of the revenue cycle, and during the post-test, they may have answered questions relating to the fourth phase of the revenue cycle.

After the students completed the pre-test quiz, they were informed that they would be playing the Jeopardy game with AIS exam topics similar to the quiz they just performed. The students were told they would be playing for bonus points and informed of the game rules and scorekeeping procedures. Due to time constraints, not all of the available pre/post quiz material (Jeopardy questions) was covered. After the Jeopardy game was stopped, and without prior knowledge, the students were again given a similar comprehensive post-test quiz.

To assess the effectiveness of the Jeopardy game on learning, the pre/post quiz results were compared. The comprehensive quiz material that was covered during the Jeopardy game was compared to the pre/post test questions and those questions were identified. Out of twenty comprehensive quiz questions, there were eight pre/post test questions material that were not covered during the Jeopardy game and twelve pre/post test questions material that were covered during the Jeopardy game. Since there were an uneven number of questions, the students' results were converted to accuracy scores (percentages correct) for comparison purposes.

Comparing only the pre-test scores, there was no significant difference in the mean accuracy scores between the eight questions (46\%) that were not covered during the Jeopardy game and twelve questions (45\%) that were covered during the Jeopardy game $(\mathrm{t}=.31, \mathrm{p}$-value $=.76)$. Comparing the pre/post test scores, there was no significant difference in the mean accuracy scores for the eight questions that were not covered during the Jeopardy game (pre-test score $46 \%$ vs. post-test score $47 \%, \mathrm{t}=.34$, $\mathrm{p}$-value $=.74$ ). However, there was a significant difference in the pre/post test mean accuracy scores for the twelve questions that were covered during the Jeopardy game (pre-test score $45 \%$ vs. post-test score $61 \%, \mathrm{t}=5.28$, p-value $=.00)^{1}$. This result was expected and reflected that the Jeopardy game increased the students understanding of the exam material covered while playing the game. Mean accuracy results and comparisons are presented in figure 1 and table 1 .

In addition to the pre/post test quizzes, students were asked to indicate the extent to which they agreed or disagreed with statements regarding enjoyment of the exercise and their perceived learning from playing the Jeopardy game. The responses measured on a Likert-type Scale from 1 (Strongly Disagree) to 7 (Strongly Agree) indicate that the students enjoyed (mean 6.4) the exam review using the Jeopardy game format and the students agreed that the game increased their understanding (mean 5.7) of the exam material. Anecdotal, observational evidence offered by the authors suggests that the students appeared to be learning when they viewed the questions and shared with their group members what they thought the correct answers were and whether they should attempt to answer the questions as a team (buzz in).

While the game was utilized in an undergraduate AIS setting, it could easily be adapted to any course by simply changing the questions and corresponding answers. A limitation of this study is that it did not test other learning strategies or that the Jeopardy game is the best way to learn, only that learning appeared to take place. Another limitation suggested by Rotter (2004) is that students with learning disabilities may not benefit as much from reviewing exam material in this manner as those students who do not have learning disabilities. 
Figure 1 - Mean Accuracy Scores From the Pre/Post Tests

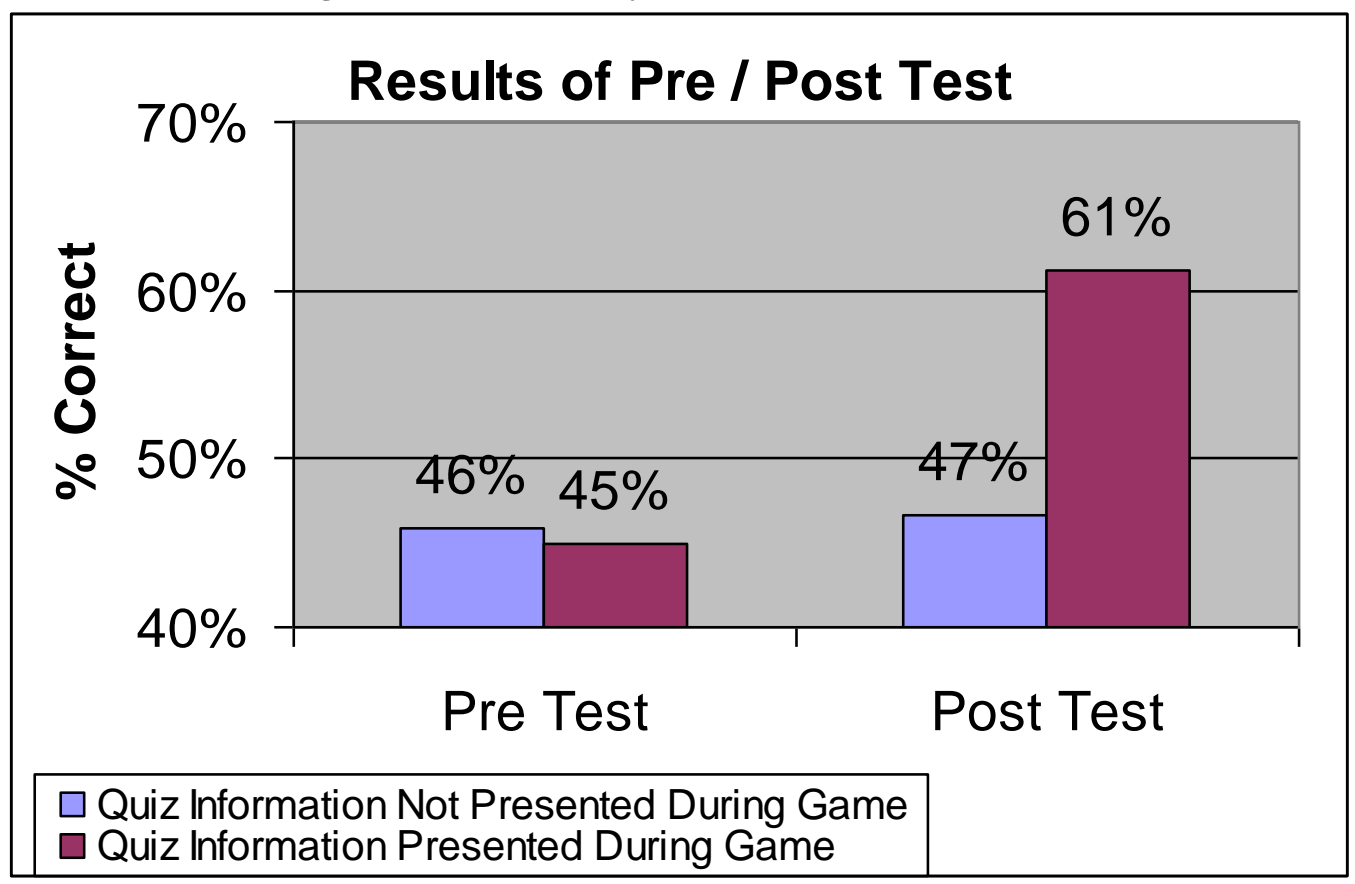

Table 1 - Mean Accuracy Scores and Results of the Pre/Post Test

\begin{tabular}{|l|c|c|}
\hline Items & $\begin{array}{c}\text { Mean (Std Dev) Pre- } \\
\text { Test Accuracy Score }\end{array}$ & $\begin{array}{c}\text { Mean (Std Dev) Post- } \\
\text { Test Accuracy Score }\end{array}$ \\
\hline $\begin{array}{l}\text { Eight questions where the quiz information was not presented during the } \\
\text { Jeopardy game. }\end{array}$ & $46 \%^{\mathrm{ab}}(2.12)$ & $47 \%^{\mathrm{b}}(2.34)$ \\
\hline $\begin{array}{l}\text { Twelve questions where the quiz information was presented during the } \\
\text { Jeopardy game. }\end{array}$ & $45 \%^{\mathrm{ac}}(2.11)$ & $61 \%^{\mathrm{c}}(2.58)$ \\
\hline
\end{tabular}

${ }^{\mathrm{a}}$ There was no significant difference in pre-test mean accuracy scores $(\mathrm{t}=.31, \mathrm{p}$-value $=.76)$.

${ }^{\mathrm{b}}$ There was no significant difference in pre/post test mean accuracy scores (pre-test score $46 \%$ vs. post-test score $47 \%$ ) for the eight questions that were not covered during the Jeopardy game $(\mathrm{t}=.34$, $\mathrm{p}$-value $=.74)$.

${ }^{c}$ There was a significant difference in the pre/post test mean accuracy scores (pre-test score $45 \%$ vs. post-test score $61 \%$ ) for the twelve questions that were covered during the Jeopardy game $(\mathrm{t}=5.28, \mathrm{p}$-value $=.00)$

\section{CONCLUSIONS}

This study extended prior literature by examining the effects of using the TV game Jeopardy in an AIS setting to review exam material. While prior studies have used paper and pencil to present the game, this study developed the game using Microsoft Excel. Excel offers the natural advantage of being able to calculate items such as group's scores or remaining points in the game. In addition, hyperlinks and macros were employed to allow the game to be played with seamless transition between worksheets. The worksheets were designed to allow instructors to easily switch between topics/questions or to insert their own topics/questions.

In addition to the game delivery tool contribution, a pre/post test was conducted to examine the effects of playing the Jeopardy game on students' understanding of AIS exam material. Overall the results indicate that the Jeopardy game did significantly increase the student's understanding of the AIS exam material that was covered. While alternative review methods were not tested, the students requested that they be allowed to play the Jeopardy game again because it was so much fun and they felt that they were learning. 


\section{ENDNOTES}

1. Wilcoxon signed rank tests also reflected a significant increase $(Z=4.38$, $p$-value $=.001)$ in the level of understanding of the exam material covered.

\section{REFERENCES}

1. Burns, M. T. and M. Benoit, "Nutrition Jeopardy," Journal of Nutrition Education and Behavior, Vol 34, No. 2, 117-118, 2002.

2. Fox-Cardamone, L and Rue, S., "Students' Response to Active Learning Strategies, An Examination of Small Group and Whole-Class Discussion," Research for Educational Reform, Vol. 8 No. 3, pp. 3-13, 2003.

3. Haywood, M.E., McMullen, D.A. and Wygal, D.E., "Using Games to Enhance Student Understanding of Professional and Ethical Responsibilities," Issues in Accounting Education, Vol. 19, No. 1, pp. 85-99, 2004.

4. Keck, M, “A Final Exam Activity Based on the Jeopardy Format," Journal for Chemical Education, Apr 2000, p. 483, 2000.

5. Romney, M. and P. Steinbart, Accounting Information Systems Ninth edition, Prentice Hall, Upper Saddle River, NJ, 2003.

6. Rotter, K., "Modifyi ng Jeopardy! Games to Benefit All Students," Teaching Exceptional Children, Vol. 36, No. 3, pp. 58-62, 2004 